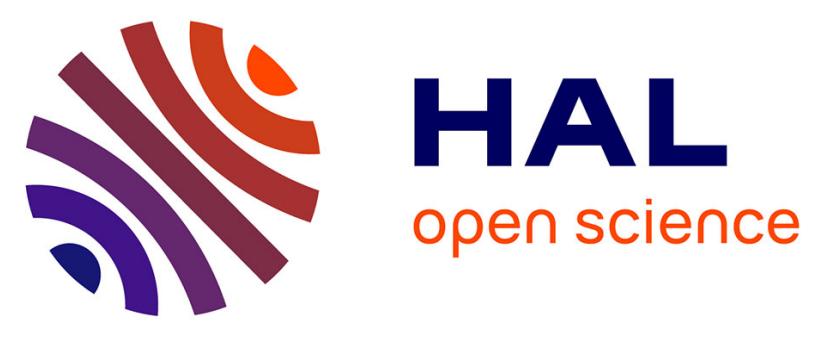

\title{
Impact of variable frequency microwave and rapid thermal sintering on microstructure of inkjet-printed silver nanoparticles
}

\author{
Romain Cauchois, Mohamed Saadaoui, Abdelwahhab Yakoub, Karim Inal, \\ Béatrice Dubois-Bonvalot, Jean-Christophe Fidalgo
}

\section{To cite this version:}

Romain Cauchois, Mohamed Saadaoui, Abdelwahhab Yakoub, Karim Inal, Béatrice Dubois-Bonvalot, et al.. Impact of variable frequency microwave and rapid thermal sintering on microstructure of inkjet-printed silver nanoparticles. Journal of Materials Science, 2012, 47 (20), pp.7110-7116. 10.1007/s10853-012-6366-6 . emse-00673215

\section{HAL Id: emse-00673215 \\ https://hal-emse.ccsd.cnrs.fr/emse-00673215}

Submitted on 2 Oct 2012

HAL is a multi-disciplinary open access archive for the deposit and dissemination of scientific research documents, whether they are published or not. The documents may come from teaching and research institutions in France or abroad, or from public or private research centers.
L'archive ouverte pluridisciplinaire HAL, est destinée au dépôt et à la diffusion de documents scientifiques de niveau recherche, publiés ou non, émanant des établissements d'enseignement et de recherche français ou étrangers, des laboratoires publics ou privés. 


\title{
Impact of variable frequency microwave and rapid thermal sintering on microstructure of inkjet-printed silver nanoparticles
}

\author{
Romain Cauchois ${ }^{1,2}$, Mohamed Saadaoui ${ }^{2}$, Abdelwahhab Yakoub ${ }^{2}$, Karim Inal $^{2}$, \\ Beatrice Dubois-Bonvalot ${ }^{1}$, Jean-Christophe Fidalgo ${ }^{1}$ \\ ${ }^{1}$ Department of Innovation and Manufacturing Technologies, Gemalto, Avenue du Pic de Bertagne, 13881 Gemenos - France \\ ${ }^{2}$ Centre Microélectronique de Provence, Ecole Nationale Supérieure des Mines de Saint-Etienne, 880 avenue de Mimet, 13541 \\ Gardanne - France
}

\section{Abstract}

The effect of thermal profile on microstructure is studied in the frame of thin films deposited by inkjet-printing technology. The role of sintering temperature and thermal ramp is particularly investigated. Fast heating ramps exhibit coarse grains and pores, especially when a hybrid microwave curing is performed. This enhanced growth is attributed to the quick activation of densifying sintering regimes without undergoing thermal energy loss at low temperature. Microstructural evolution of various sintered inkjet-printed films is correlated with electrical resistivity and with the Young's modulus determined by nanoindentation. A strong link between those three parameters is highlighted during experiments giving credit to either a surface or a fully volumetric sintering, according to the process. Sintering is then mainly triggered by surface mass transfer or by grain boundary diffusion respectively. Silver thin-films with an electrical resistivity 4 to 5 times higher than the bulk has been reached in a few minutes and with a Young's modulus of $38 \mathrm{GPa}$.

Keywords: fast sintering of nanoparticle, inkjet printing, microstructure, hybrid variable frequency microwave (HVFM), rapid thermal anneal (RTA)

\section{Introduction}

As an alternative technology to replace lithographic process, direct printing of metallic colloidal suspensions can be used to fabricate high resolution patterns especially for electronic applications, such as antennas and conductive redistribution lines [1-3]. In the past few years, the use of metallic nanoparticles has undergone major development in microelectronics thanks to the advanced achievements in the development of inks, printing and sintering tools.

To preserve electronic components functionalities, a limited sintering temperature below $300^{\circ} \mathrm{C}$ is required. This reason first motivated the use of nanoparticles for their proficiency to sinter at low temperature given their thermodynamic size effect $[4,5]$. Nonetheless, the absence of any compacting step requires the exploration of novel sintering approaches to achieve sufficient nanoparticles coalescence. In this frame, several sintering processes (thermal oven, selective laser, microwave and photonics) have been investigated to optimize the annealing of those thin films [6-8] with respect to the underneath substrate.

Sintering is the capacity for small particles, whether nano-sized or micron-sized, to merge through the formation of a neck. This material continuum is generated by several atomic diffusion mechanisms which operate concurrently in the material. According to the applied thermal treatment, one or several of those mechanisms will be activated. Conventionally, diffusion mechanisms are distinguished in two categories: densifying and non-densifying mechanisms. While densification usually tends to involve bulk diffusion routes, non-densifying surface diffusions mechanisms are easily activated by temperature. 
Previous results have been reported on the impact of sintering temperature and time on the final microstructure of silver nanoparticles $[9,10]$.

In this study, fast sintering techniques are explored for low temperature initiation of densifying regimes. Their prospective advantages on electrical and mechanical properties compared to conventional sintering in oven are developed.

\section{Experimental details}

In this study, a commercially available colloidal suspension with a silver nanoparticle content of $20 \mathrm{wt} \%$ was purchased from Sun Chemical. As depicted on Figure 1, nanoparticles present an average diameter of 25-30 nm. They are dispersed in a liquid vehicle composed of polar solvents: ethanol, ethylene glycol and glycerol. Additionally, in order to avoid agglomeration and sedimentation, silver nanoparticles are coated with a capping agent.

This colloidal dispersion is deposited in thin film onto a n-type (100) silicon substrate using a drop-on-demand inkjet printing technology. Deposition was performed at room temperature using a 256 nozzle Spectra printhead integrated in an in-line prototype developed in the lab (JetPac). In this system, droplets are heated at $39{ }^{\circ} \mathrm{C}$ and propelled by the means of a $100 \mathrm{~V}$ bipolar pulse sent to a piezoelectric printhead. A consecutive thermal treatment is finally applied in order to evaporate solvents and to initiate the sintering process.

Electric conduction in printed thin films is achieved by a sintering step through two techniques: Rapid Thermal

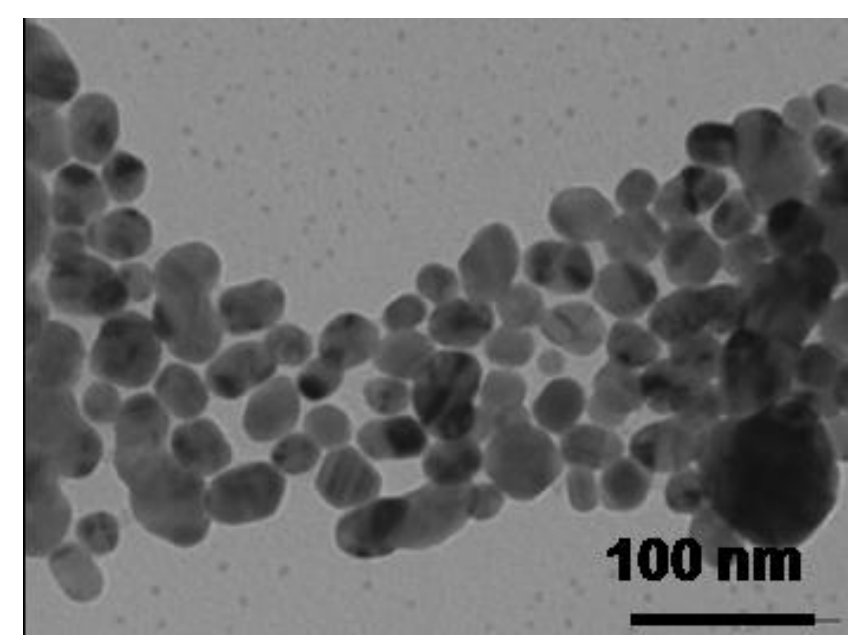

Figure 1: Transmission electron micrograph of silver nanoparticles used in this work.
Annealing (RTA) and Hybrid Variable Frequency Microwaves (HVFM) sintering. RTA curing was conducted in a $\mathrm{N}_{2}$ atmosphere with halogen lamps in a JetFirst 100 oven from Jipelec. Nitrogen atmosphere was used to avoid surface contamination by sulfur elements. HVFM curing was performed in air in a MicroCure 2100 oven manufactured by Lambda Technologies. The combination of microwave and conductive heating in a hybrid configuration had been performed where the silicon substrate is acting as a susceptor. Samples were processed using a variable frequency mode centered around $6.425 \mathrm{GHz}$ with a bandwidth of $0.75 \mathrm{GHz}$ and a sweep rate of 0.1 second. After curing, the average thickness of printed films is comprised between $2 \mu \mathrm{m}$ and $3 \mu \mathrm{m}$ according to the shrinkage induced by the thermal profile.

In both cases, a treatment of 15 minutes was performed at different temperatures between $130{ }^{\circ} \mathrm{C}$ and $300{ }^{\circ} \mathrm{C}$ with several thermal ramps comprised between 0.1 and $150{ }^{\circ} \mathrm{C} / \mathrm{s}$ for the RTA and between 0.1 and $10{ }^{\circ} \mathrm{C} / \mathrm{s}$ for HVFM process. It should be noted that a ramp of $0.1{ }^{\circ} \mathrm{C} / \mathrm{s}$ is equivalent to thermal condition reached in a conventional atmospheric oven. In both sintering systems, a feedback controller regulated the temperature ramp by adjusting the forward power level as shown on Figure 2.

The effect of temperature on the solvents evaporation was identified using Differential Scanning Calorimetry (DSC) from TA Instrument. Experiments were conducted on printed samples from room temperature to $230{ }^{\circ} \mathrm{C}$ at $10{ }^{\circ} \mathrm{C} / \mathrm{s}$ with a constant flow of $50 \mathrm{~mL} / \mathrm{min}$ of $\mathrm{N}_{2}$.

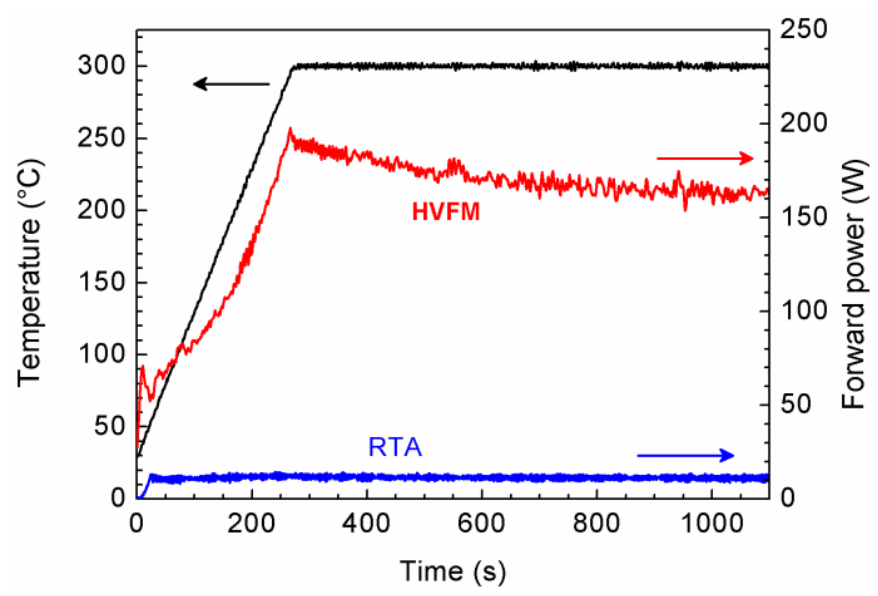

Figure 2: Temperature and forward power profiles with respect to time for both RTA and HVFM configurations for a sintering temperature of $300{ }^{\circ} \mathrm{C}$ and a ramp of $1{ }^{\circ} \mathrm{C} / \mathrm{s}$. 
Microstructural evolution was characterized on the basis of SEM micrographs performed in a fieldemission gun scanning electron microscope (Ultra 55 from Zeiss) with secondary electron detector operating at $30 \mathrm{kV}$. An image contrast analysis was carried out using ImageJ software from NIH to differentiate grains from the thin film surface and to determine their respective size.

Electrical measurements were performed using a fourpoint probe equipment from Jandel on $1 \mathrm{~cm}^{2}$ printed thin films for each condition. A nominal current of $100 \mathrm{~mA}$ was used to determine the sheet resistance.

Eventually, nanoindentation measurements were performed with a Nanoindenter XP from MTS to extract the Young's modulus of printed samples. A Berkovich diamond tip was operated in Continuous Stiffness Measurement (CSM) mode at a nominal strain rate of $0.05 \mathrm{~s}^{-1}$. The contact stiffness was measured with an indenter oscillation with peak-to-peak amplitude of $2 \mathrm{~nm}$ and a frequency of $45 \mathrm{~Hz}$ during the holding segment.

\section{Results and discussion}

\subsection{Microstructural evolution with respect to the thermal conditions}

While heat transfer by conduction and radiation is mainly affecting the film interfaces in a RTA oven, microwaves provide rapid volumetric heating. Thus, microwave heating usually achieve more uniform sintering since the energy is dissipated within the layer due to internal friction between atoms with a thermal flux moving outward from the layer core [11]. While bulk metals are usually assumed to reflect microwave radiations, a coupling can be achieved with metallic powder [12]. The absorbed power per unit volume, $\mathrm{P}$ is given by:

$$
P=\frac{E^{2}}{\rho}=\omega \varepsilon^{\prime \prime} E^{2}
$$

where $\rho$ is the electrical resistivity, $\omega=2 \pi f$ is the angular frequency of the microwave radiation, $\varepsilon$ " is the dielectric loss factor and $\mathrm{E}$ is the amplitude of the electromagnetic field.

Given the high electrical conduction of metals, microwave radiations only interact with the extreme surface of metals, known as the skin depth defined by:

$$
\delta_{p}=\frac{c \varepsilon_{0}}{2 \pi f \varepsilon^{\prime \prime}}=\left(\frac{2 \rho}{\omega \mu}\right)^{1 / 2}
$$

where $\mu$ is the absolute magnetic permeability of the material and $\varepsilon_{0}$ is the permittivity of the free space. So that, for a frequency of $6.425 \mathrm{GHz}$, the electromagnetic wave is confined within $80 \mathrm{~nm}$ of silver. Since nanoparticles size is well below this value, the variable electromagnetic field across the particle is uniform and causes volumetric heating without any arcing [13].

As mentioned above, a feedback loop is required to control the system temperature through the forward power. This control is assured by an infrared pyrometer which measures the system temperature and consequently adjusts the forward power of the microwave generator. Since inkjet-printed layers vary from liquid to solid state, emissivity is expected to change accordingly during the heating step. A calibration thus has to be performed on the temperature range. As shown on Figure 3, emissivity drops from 0.78 to 0.11 between $120{ }^{\circ} \mathrm{C}$ and $130{ }^{\circ} \mathrm{C}$. As indicated by the DSC thermogram plotted on Figure 3, endothermic peaks corresponding to the evaporation of solvents are ending in the same range of temperature. The consecutive increase of the heat flow can directly be related to the initiation of the sintering process. Indeed, as soon as the last solvent is removed, the deposit changes from a liquid to a solid phase where contact between nanoparticles is enabled and atomic diffusion processes initiated.

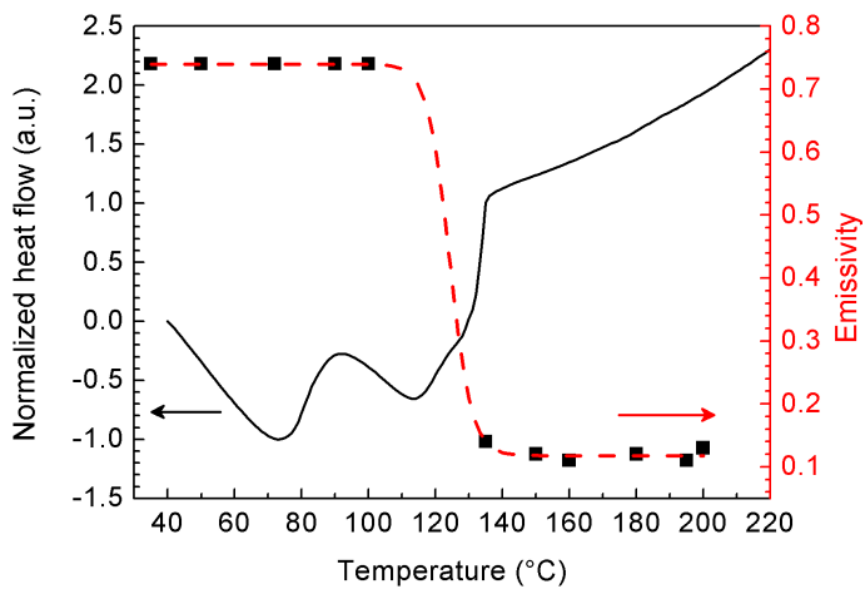

Figure 3: Exothermic thermogram of the nanoparticle-based ink deposited on a silicon substrate obtained by DSC (plain line) and variation in infrared emissivity calibrated with a pyrometer and a thermocouple on inkjet-printed ink (dotted line). 
It should be noted from Figure 3 that the boiling point of solvents is reduced when a few pico-liters are inkjetprinted on silicon, compared to milliliter droplets casted in a conventional aluminum pan used for DSC. Indeed, ethanol, ethylene glycol and glycerol are tabulated to evaporate at $79^{\circ} \mathrm{C}, 197{ }^{\circ} \mathrm{C}$ and $290{ }^{\circ} \mathrm{C}$ respectively. More, during the microwave curing process, solvent evaporation is all the more quick that they have polar groups, which concerns ethanol, ethylene glycol and glycerol [14].

If further interest is put on the evolution of surface microstructure of printed thin films, SEM micrographs exhibit a very high dependency to the thermal cycle and especially to the dwell temperature (see Figure 4 and 5). During the heating treatment, both coarsening and densification are occurring. While RTA curing seems to induce a partial sintering of the film with a high number of small porosities, a bimodal distribution of grains is observable at $300{ }^{\circ} \mathrm{C}$ with HVFM curing (see Figure 5). Impact of the microwave curing effect is particularly noticeable with an enhanced coarsening and densification due to the previously mentioned coupling with nanosized crystals.
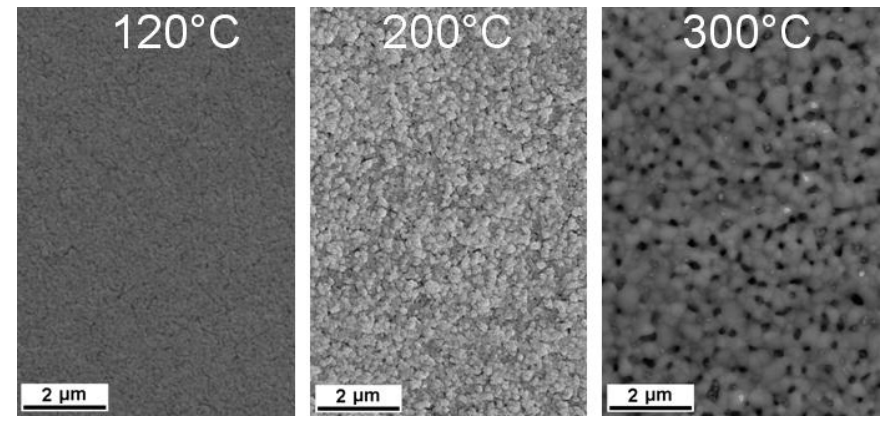

Figure 4: Microstructural evolution of silver thin films surface after being sintered in a RTA oven during 15 min with a thermal ramp of $10{ }^{\circ} \mathrm{C} / \mathrm{s}$.
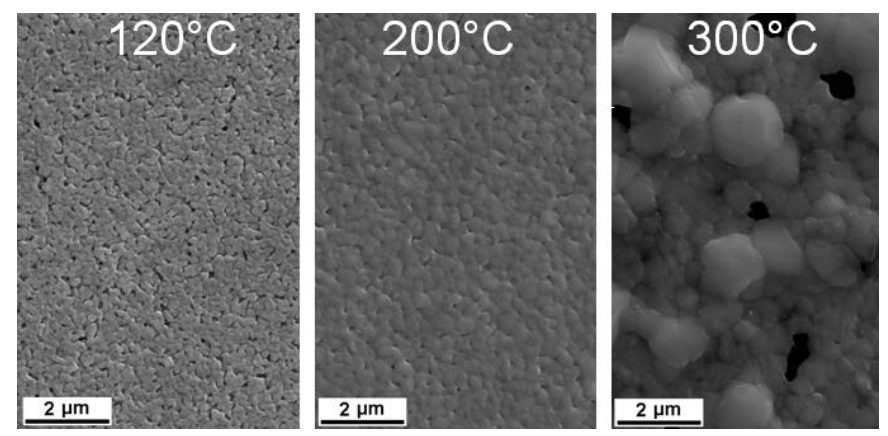

Figure 5: Microstructural evolution of silver thin films surface after being sintered in a HVFM oven during 15 min with a thermal ramp of $10{ }^{\circ} \mathrm{C} / \mathrm{s}$.

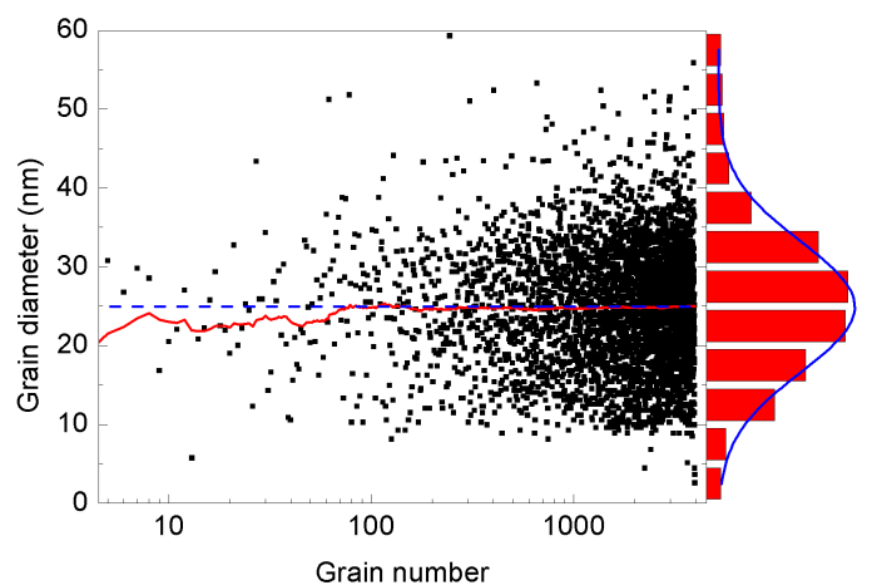

Figure 6: Grain diameter of 4000 grains on the surface of a green deposit exhibiting the average value (blue dashed line) and the Gaussian distribution of grain size (on the right).

These images have been treated using ImageJ to extract the distribution of grain size, based on the variation of contrast at grain boundaries. As seen in Figure 6 in the case of green-state powder, the grain size is following a Gaussian distribution centered on $25 \mathrm{~nm}$ with a standard deviation of $7 \mathrm{~nm}$. This operation is repeated for each sample.

For the film sintered at $300{ }^{\circ} \mathrm{C}$ under $10{ }^{\circ} \mathrm{C} / \mathrm{s}$ in HVFM oven, the bimodal distribution of grain size is centered on $300 \mathrm{~nm}$ and $1 \mu \mathrm{m}$. The first distribution is similar in size and shape to the surface microstructure after being sintered at $200{ }^{\circ} \mathrm{C}$ (see Figure 5). This distribution is thus attributed to a normal grain growth taking place in the plane. The second one results from an out-of-plane abnormal grain growth induced by the constraint of the thin-film pinning on the substrate [15] and by the additional coupling with strong microwave radiations during the $15 \mathrm{~min}$ exposure. Moreover, the pores have migrated and merged to a nearly bulk polycrystalline structure in order to reduce the surface energy. Indeed, in this case, the excess energy per unit area at the interface with the substrate will tend to promote the growth of grains with $<111\rangle$ orientation at the expense of the stagnant matrix of grains with other orientations. As demonstrated by Frost [16], this secondary grain growth can thus result in the development of bimodal grain size distributions.

The final grain size after an isothermal sintering of 15 min is reaching an asymptotic value as soon as the sintering ramp exceeds $25{ }^{\circ} \mathrm{C} / \mathrm{s}$. Such rapid thermal ramps indeed enable the activation of grain growth and 


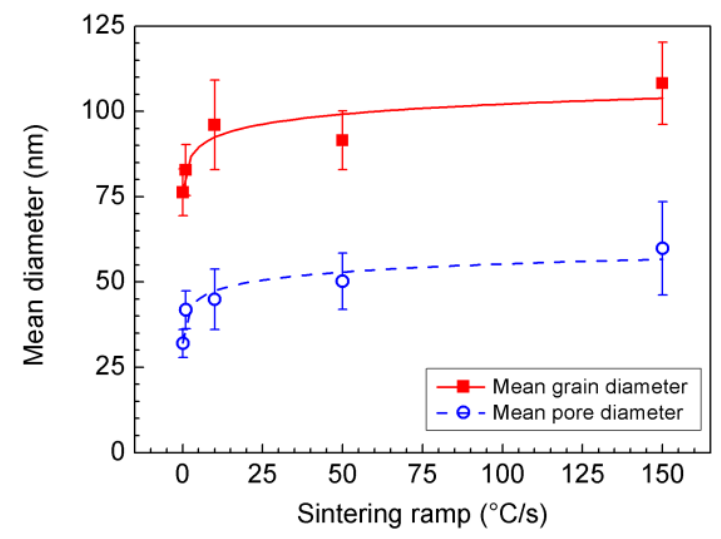

Figure 7: Evolution of grain and pore mean diameter with the sintering ramp for a treatment of $300{ }^{\circ} \mathrm{C}$ during 15 minutes in RTA oven.

advanced sintered states avoiding energy consumption in non-densifying regimes. Since dominant diffusion mechanisms are surface-driven at low temperature, fast sintering allows saving thermal energy for densification and grain growth. Figure 7 shows their impact on the evolution of the mean grain diameter obtained by RTA sintering.

From the data, an empirical behavior law can be derived for the grain diameter $\mathrm{G}$ during an isothermal sintering:

$$
G=G_{0}+66.2 \cdot\left[1-\exp \left(-14.9 \frac{d T}{d t}\right)\right]
$$

where $G_{0}$ is the initial size of nanoparticles in the greenstate $\left(\mathrm{G}_{0}=25 \mathrm{~nm}\right)$.

Obviously, numerical constant are related to the specific sintering time and temperature. A lower sintering time or temperature would result in smaller grains due to the activation of diffusion mechanisms only at the grain surface. This law thus enables prediction of the final microstructure after performing the RTA curing at $300{ }^{\circ} \mathrm{C}$ during $15 \mathrm{~min}$. If a particular electrical or mechanical property value is desired for a given application, tailoring the film microstructure is thus more easily achieved for thermal ramp comprised between 0.1 and $25^{\circ} \mathrm{C} / \mathrm{s}$.

\subsection{Impact of heating conditions on electrical and mechanical properties of porous printed thin films}

Microstructure evolution has been reported to impact the electrical properties of materials. In the present study, a huge shrink in electrical resistivity

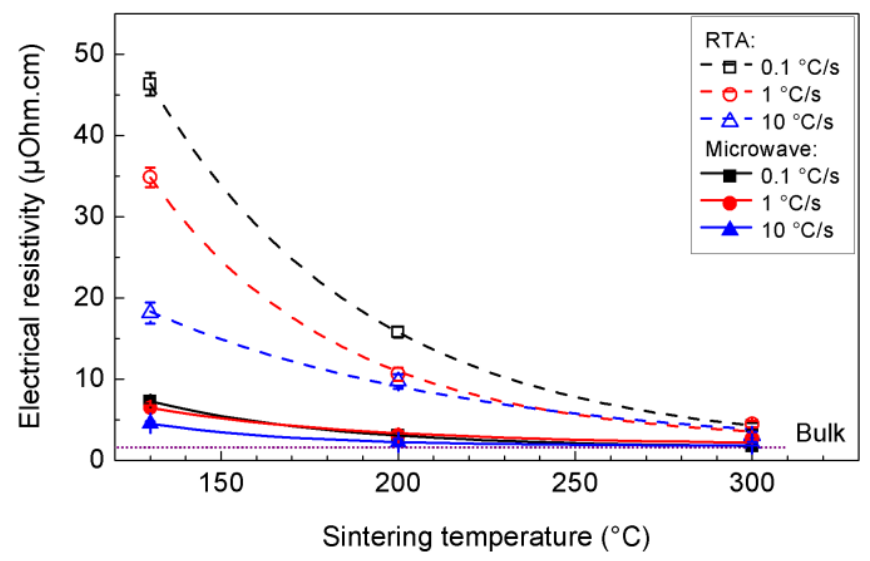

Figure 8: Evolution of the electrical resistivities of printed thin film after being sintered $15 \mathrm{~min}$ in hybrid microwave oven (plain lines) or in RTA (dashed lines).

is particularly observable for samples prepared in RTA, while those prepared in HVFM quickly exhibit resistivities below $8 \mu \Omega \cdot \mathrm{cm}$ (see Figure 8 ). In both cases, the highest the thermal ramp is, the lower the electrical resistivity will be. Nonetheless, since all curves are converging, the asymptotic value seems relatively independent from the ramp and more related to the sintering temperature.

According to the thermal ramp, electrical resistivity achieved at $300{ }^{\circ} \mathrm{C}$ by RTA is 4 to 5 times the bulk resistivity of silver $(1.62 \mu \Omega \cdot \mathrm{cm}$ [17]) which is consistent with literature. This result is clearly due to a partial sintering of the film which presents a high number of porosities (see Figure 4) and to high reflectivity at grain boundaries. Indeed, grain boundaries are acting as scattering sources for electrons [18]. Limiting the number of those partial reflectors will thus tend to enhance the electrical resistivity of the film. Since grain coarsening is driven by surface/interface minimization, the fewer the grains are, the fewer the grain boundaries there will be. In the case of HVFM sintering, the density reached at $300{ }^{\circ} \mathrm{C}$ is close to a fully dense polycrystalline silver film despite the presence of residual porosities. This deposit exhibits a very low resistivity at $2.1 \mu \Omega \cdot \mathrm{cm}$ which deviates from the bulk value because of electrons scattering at grain boundaries. For a better understanding of the dissimilar behavior of RTA and HVFM sintering, further consideration to the underlying mechanisms is required. Mechanical properties of materials are greatly impacted by the presence of pores [19]. To determine how the porosity fraction evolves according to the sintering conditions, standard porosimetry measurements turns out to be inefficient for nanoparticulate thin films. A 
convenient way to assess porosimetry is then to consider its indirect impact on the evolution of mechanical stiffness, via nanoindentation for example. A model is thus required to process the data and to extract the porosity fraction.

According to the model of the cellular structure developed by Gibson and Ashby [20] and assuming an elastic deformation of the open cell porous solid, the Young's modulus of the inkjet-printed film is correlated to the bulk one and to their relative density by [21]:

$$
E_{f}=k \cdot E_{0} \cdot\left(\frac{\rho_{f}}{\rho_{0}}\right)^{2}
$$

where $\mathrm{k}$ is a geometric constant equal to 1.06 for an open cell foam, E and $\rho$ are respectively the Young's modulus and the density of the considered material and the subscripts 0 and $f$ are related to the bulk material or the thin film, respectively.

The Young's moduli of printed thin films after curing were determined by nanoindentation using the OliverPharr model for several thermal profiles [22]. Load vs displacement curves with respect to the thermal ramp or the sintering temperature are presented on Figure 8 for samples sintered in RTA oven.

As expected, the impact of porosity fraction and microstructure is notable with a decrease of the mechanical stiffness when density is low. However, the thermal ramp seems to have little effect on the Young's modulus in the range comprised between 0.1 and $10{ }^{\circ} \mathrm{C} / \mathrm{s}$. In this case, for a given temperature, variation of the modulus is indeed always limited within $5 \mathrm{GPa}$. Regarding the impact of the sintering temperature, a gain of 20 to $35 \%$ is observed between film cured at $130{ }^{\circ} \mathrm{C}$ or at $300^{\circ} \mathrm{C}$.

With $38 \mathrm{GPa}$, the maximum value of the Young's modulus is achieved for high sintering temperature operated at low thermal ramp. This value is roughly half the value of bulk polycrystalline silver at $82 \mathrm{GPa}$ [17] indicating a very high proportion of pores. Those values should be considered with caution given the inherent difficulty to derive a nanoindentation model for porous thin films. Indeed, during the indentation load, both the underlying substrate and the progressive collapse of the porous structure are impacting the stiffness measurements.

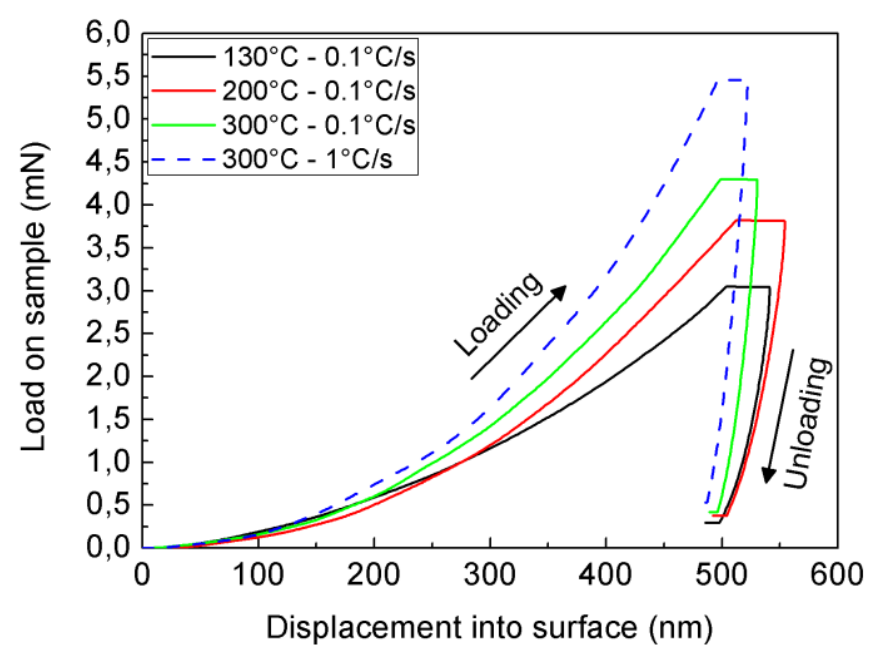

Figure 9: Impact of sintering temperature and ramp on loaddisplacement curves of printed silver thin films.

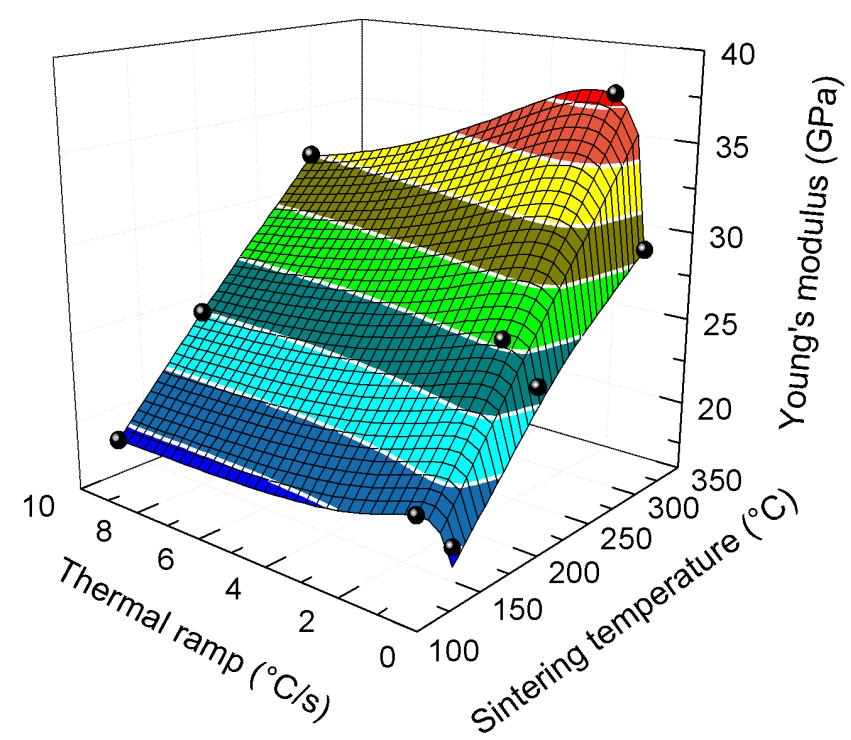

Figure 10: Color map surface of the Young's modulus according to the thermal ramp and sintering temperature for an inkjet-printed thin film on silicon sintered in a RTA oven.

The relative density of the film can be estimated using the above-mentioned model of Gibson and Ashby. While it is limited to $46 \%$ at $130^{\circ} \mathrm{C}$, the relative density could increase up to $66 \%$ when heated at $300{ }^{\circ} \mathrm{C}$ with a ramp of $1{ }^{\circ} \mathrm{C} / \mathrm{s}$. During the whole process with RTA, those values indicate that only intermediate stage sintering is achieved. On the contrary, microwave sintering is believed to reach final stage sintering when densification is close to the bulk. 


\section{Conclusions}

Fast sintering of inkjet-printed thin-films has been implemented using rapid thermal annealing and microwave ovens. Such ramps enable the activation of grain growth and advanced sintered states avoiding energy consumption in non-densifying regimes. Impact of the thermal cycle has been demonstrated both on grain and pore with a rapid stabilization. Microstructural evolution of various sintered inkjetprinted films is correlated with electrical resistivity and with the Young's modulus determined by nanoindentation. A strong link between those three parameters is highlighted during experiments giving credit to either a surface or a fully volumetric sintering, according to the process. In particular, hybrid microwave heating has proven its proficiency to achieve low resistive films or lines, compared to conventional sintering techniques or even rapid thermal annealing. Future work will concern the derivation of activation energies of silver nanoparticles grain growth observed during sintering. Indeed, those energies can suitably be used for the development of numerical simulation for nanoparticles sintering.

\section{Acknowledgements}

The authors would like to acknowledge the helpful contribution of Sergio Sao-Joao, from the department of Materials Science and Structures (SMS) of ENSM-SE, for TEM analysis.

\section{References}

[1] J. Szczech, C. Megaridis, D. Gamota, and J. Zhang, IEEE Transactions on Electronics Packaging Manufacturing 25, 26 (2002).

[2] V. Pekkanen, M. Mäntysalo, K. Kaija, P. Mansikkamäki, E. Kunnari, K. Laine, J. Niittynen, S. Koskinen, E. Halonen, and U. Caglar, Microelectron. Eng. 87, 2382 (2010).

[3] J.-W. Kim, Y.-C. Lee, J.-M. Kim, W. Nah, H.-S. Lee, H.-C. Kwon, and S.-B. Jung, Microelectron. Eng. 87, 379 (2010).

[4] T. Castro, R. Reifenberger, E. Choi, and R. P. Andres, Phys. Rev. B 42, 8548 (1990).

[5] P. Buffat and J.-P. Borel, Phys. Rev. B 13, 2287 (1976).

[6] A. T. Alastalo, T. Mattila, M. L. Allen, M. J. Aronniemi, J. H. Leppäniemi, K. A. Ojanperä,
M. P. Suhonen, and H. Seppä, MRS Proceedings, volume 1113 (2008).

[7] J. Perelaer, M. Klokkenburg, C. E. Hendriks, and U. S. Schubert, Adv. Mater. 21, 4830 (2009).

[8] A. Chiolerio, G. Maccioni, P. Martino, M. Cotto, P. Pandolfi, P. Rivolo, S. Ferrero, and L. Scaltrito, Microelectron. Eng. 88, 2481 (2011).

[9] J. R. Greer and R. A. Street, Acta Mater. 55, 6345 (2007).

[10] R. Cauchois, M. Saadaoui, K. Inal, B. DuboisBonvalot, and J.-C. Fidalgo, MRS Proceedings, volume 1335(2011).

[11] M. Gupta, E. Leong, and W. Wong, Microwaves and metals, John Wiley \& Sons, 2007.

[12] R. Roy, D. Agrawal, J. Cheng, and S. Gedevanishvili, Nature 399, 668 (1999).

[13] S. Takayama, G. Link, S. Miksch, M. Sato, J. Ichikawa, and M. Thumm, Powder Metall. 49, 274 (2006).

[14] C. Gabriel, S. Gabriel, E. H. Grant, E. H. Grant, B. S. J. Halstead, and D. Michael P. Mingos, Chem. Soc. Rev. 27, 213 (1998).

[15] J. Greiser, P. Müllner, and E. Arzt, Acta Mater. 49, 1041 (2001).

[16] H. Frost, C. Thompson, and D. Walton, Acta Metall. Mater. 40, 779 (1992).

[17] D. Lide, CRC handbook of chemistry and physics, CRC Press, 81st edition, 2000.

[18] A. F. Mayadas and M. Shatzkes, Phys. Rev. B 1, 1382 (1970).

[19] X. Chen, Y. Xiang, and J. J. Vlassak, Journal of Material Research 21, 715 (2006).

[20] L. J. Gibson and M. F. Ashby, Cellular solids: structure and properties, Cambridge solid state science series, 1999.

[21] A. J. Birnbaum, K. J. Wahl, R. C. Y. Auyeung, and A. Piqué, J. Micromech. Microeng. 20, 077002 (2010).

[22] W. C. Oliver and G. M. Pharr, J. Mater. Res. 7, 1564 (1992). 